\title{
Bandwidth Optimization of a Textile PIFA with DGS Using Characteristic Mode Analysis
}

\author{
Bashar Bahaa Qas Elias ${ }^{1,2, * \mathbb{C}}$, Ping Jack Soh ${ }^{1,3, * \mathbb{C}}$, Azremi Abdullah Al-Hadi ${ }^{1}{ }^{\mathbb{D}}$, Prayoot Akkaraekthalin ${ }^{4}$ \\ and Guy A. E. Vandenbosch ${ }^{3}$ \\ 1 Advanced Communication Engineering (ACE) CoE, Faculty of Electronic Engineering Technology, \\ Pauh Putra Campus, Universiti Malaysia Perlis (UniMAP), Arau 02600, Malaysia; azremi@unimap.edu.my \\ 2 Department of Communication Engineering Techniques, Imam Ja'afar Al-Sadiq University, \\ Baghdad 10052, Iraq \\ 3 ESAT-WAVECORE Research Division, KU Leuven, Kasteelpark Arenberg 10, 3001 Leuven, Belgium; \\ guy.vandenbosch@esat.kuleuven.be \\ 4 Department of Electrical and Computer Engineering, Faculty of Engineering, King Mongkut's University \\ of Technology North Bangkok (KMUTNB), 1518 Pracharat 1 Rd., Wongsawang, Bangsue, \\ Bangkok 10800, Thailand; prayoot.a@eng.kmutnb.ac.th \\ * Correspondence: bashar.bahaa@sadiq.edu.iq (B.B.Q.E.); pjsoh@unimap.edu.my (P.J.S.)
}

check for updates

Citation: Elias, B.B.Q.; Soh, P.J.; Al-Hadi, A.A.; Akkaraekthalin, P.; Vandenbosch, G.A.E. Bandwidth Optimization of a Textile PIFA with DGS Using Characteristic Mode Analysis. Sensors 2021, 21, 2516. https: / /doi.org/10.3390/s21072516

Academic Editor: Luciano Tarricone

Received: 10 March 2021

Accepted: 29 March 2021

Published: 4 April 2021

Publisher's Note: MDPI stays neutral with regard to jurisdictional claims in published maps and institutional affiliations.

\begin{abstract}
This work presents the design and optimization of an antenna with defected ground structure (DGS) using characteristic mode analysis (CMA) to enhance bandwidth. This DGS is integrated with a rectangular patch with circular meandered rings (RPCMR) in a wearable format fully using textiles for wireless body area network (WBAN) application. For this integration process, both CMA and the method of moments (MoM) were applied using the same electromagnetic simulation software. This work characterizes and estimates the final shape and dimensions of the DGS using the CMA method, aimed at enhancing antenna bandwidth. The optimization of the dimensions and shape of the DGS is simplified, as the influence of the substrates and excitation is first excluded. This optimizes the required time and resources in the design process, in contrast to the conventional optimization approaches made using full wave "trial and error" simulations on a complete antenna structure. To validate the performance of the antenna on the body, the specific absorption rate is studied. Simulated and measured results indicate that the proposed antenna meets the requirements of wideband on-body operation.
\end{abstract}

Keywords: planar antennas; characteristic mode analysis; defected ground structure

\section{Introduction}

Wearable antennas have recently received considerable attention due to their costeffectiveness, light weight, flexibility, and ease of integration into clothes [1-4]. The main materials used are usually based on textiles and various flexible polymers. Generally, textile materials have a higher loss than standard conductors and will reduce total radiation efficiency. Despite that, it remains the most popular material being used to fabricate wearable antennas as conductive textiles can be directly incorporated in clothes [5-9].

Characteristic mode analysis (CMA) is a method used in electromagnetics, which provides insight into the inherent resonant characteristics of a structure by finding and examining the structure's basic modes [10-13]. Any physical object has a set of modes dependent on its structure, materials, and boundary conditions. The theory of CMA was first introduced in [14] and later refined by [15,16]. It can be very effectively used in the antenna design process. The presence of the modes is independent of the excitation. However, different types of excitations at various locations can be used to meet different operational requirements.

The defected ground structure (DGS) technique is very commonly used in literature for improving bandwidth while maintaining structural simplicity. It involves the integration of 
single or multiple slots in the ground plane of planar circuits and antennas. Such integration of DGS with antennas provides structural miniaturization and surface wave suppression, which then reduces the effects of coupling to the human user [17-20]. Conventionally, in planar microstrip circuits, a DGS is located under a microstrip line, and it perturbs the existing electromagnetic fields. Trapped electric fields give rise to the capacitive effect (C), while the surface currents around the defect cause an inductive effect (L) [21].

This work presents an optimized planar inverted-F antenna (PIFA) structure with DGS integrated on its ground plane. The optimization procedure for both the DGS shape and its location is performed by studying the resonant modes of the ground plane using the CMA approach. This consequently results in an optimized method to identify the bandwidth increase for the proposed PIFA with DGS. This approach also makes the normal resourceand time-consuming antenna optimization procedure to be more efficient. The radiator of the PIFA is designed based on a unique compact rectangular patch and is integrated with circular meandered rings.

This paper is organized as follows. The structure of the proposed antenna is first described in Section 2, followed by the simulated performance of the antenna in Section 3. The on-body evaluation of the antenna is then discussed in Section 4, followed by the measurement results and analysis in Section 5. Finally, Section 6 concludes this work.

\section{Antenna Design}

The structure of the antenna is initially based on [22]. The antenna proposed in this reference initiates the use of the chassis as part of the radiator. This increases the effective aperture of the antenna, thus enabling a more compact antenna, which is especially important for operation at lower frequencies. The structure in [22] consists of five layers:

i. a $50 \times 25 \mathrm{~mm}^{2}$ ground plane made using a $0.17 \mathrm{~mm}$ thick Shieldlt conductive textile (with conductivity, $\sigma=1.18 \times 105 \mathrm{~S} / \mathrm{m}$ ),

ii. $\quad$ a $3 \mathrm{~mm}$ thick felt substrate $(\varepsilon r=1.3, \tan \delta=0.044)$,

iii. a $5 \mathrm{~mm}$ air gap,

iv. a $1.6 \mathrm{~mm}$ thick FR4 substrate $(\varepsilon r=4.3, \tan \delta=0.044)$,

v. and a patch built using a $0.17 \mathrm{~mm}$ thick copper conductor.

This structure is shown in Figure 1a. To improve flexibility for this antenna, the rigid FR4 substrate (layer (iv)) in the previous work is replaced with a $3 \mathrm{~mm}$ thick felt in this proposed work, whereas the copper conductor in layer (v) is replaced with the $0.17 \mathrm{~mm}$ thick Shieldlt textile. To ensure a practically realizable structure, the air gap in layer (iii) from the previous work is replaced by a foam substrate $(\varepsilon r=1.06)$, as shown in Figure $1 \mathrm{~b}$.

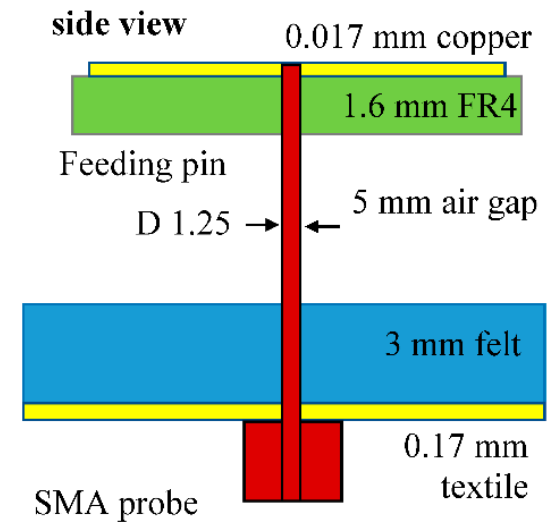

(a)

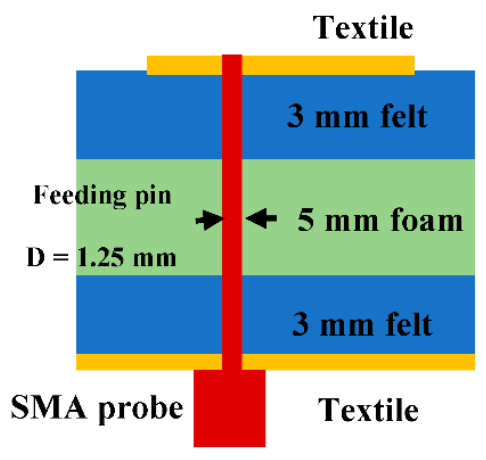

(b)

Figure 1. Side view of the antenna (a) from the previous reference [22] (@ 2019 IEEE), (b) proposed antenna.

The main radiating structure for the proposed antenna is located on the top layer in the form of a rectangular patch. It is formed using Shieldlt conductive textile. Circular 
meandered patches are then connected with the patch, as shown in Figure 2a. Similar to the previous design, the ground and lower substrate layer are also made fully using textiles. A $5 \mathrm{~mm}$ thick foam layer separates the two felt substrates. The aim of using multilayered flexible substrates is to enhance the antenna's narrow bandwidth with an increased substrate thickness. Despite enhancing the profile of the antenna, the overall thickness can still be practically integrated into winter apparel or even building insulation to provide sufficient warmth to users, while providing communication functionality due to the material's flexibility and lightness [23,24]. A standard $50 \Omega$ SMA connector is used to excite the antenna coaxially from beneath the ground plane. Details of the optimized parameters are summarized in Table 1.

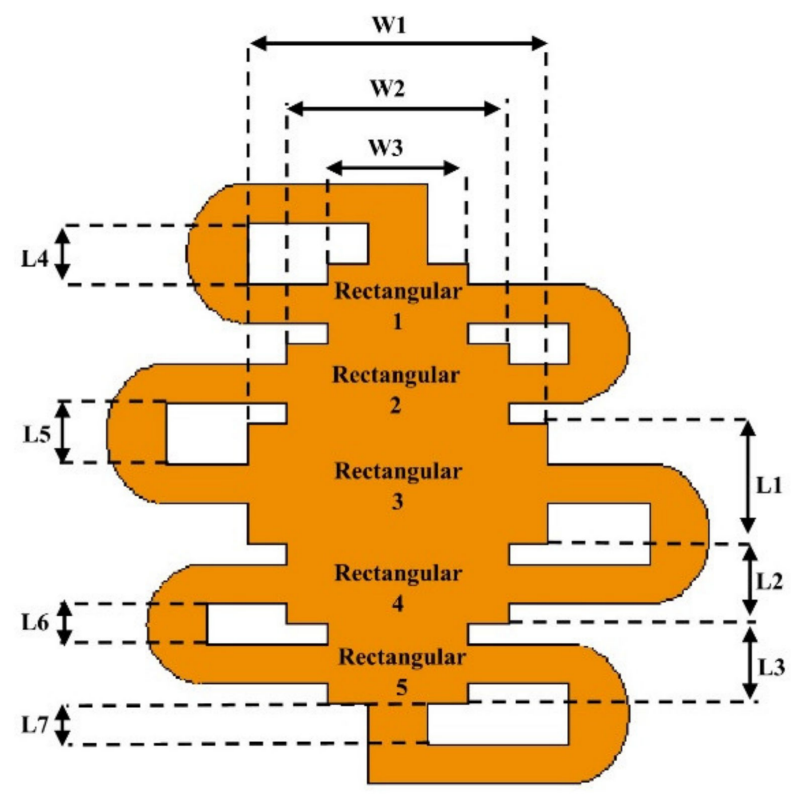

(a)

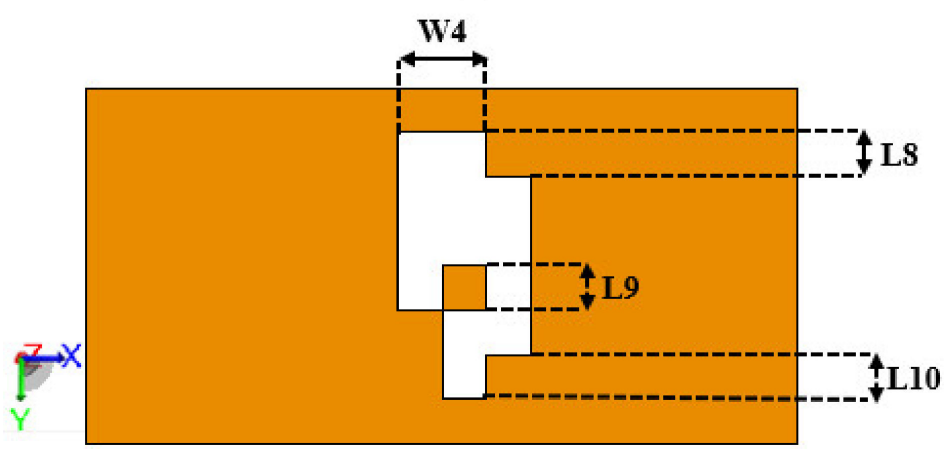

(b)

Figure 2. (a) RPCMR structure, (b) DGS structure.

Table 1. Summary of the antenna dimensions.

\begin{tabular}{cccc}
\hline Parameter & Value $(\mathbf{m m})$ & Parameter & Value $(\mathbf{m m})$ \\
\hline W1 & 9.3 & $L 4$ & 1.86 \\
W2 & 6.82 & $L 5$ & 1.86 \\
W3 & 4.34 & $L 6$ & 1.24 \\
W4 & 6.25 & $L 7$ & 1.24 \\
L1 & 3.72 & $L 8$ & 3.125 \\
L2 & 2.48 & $L 9$ & 3.125 \\
L3 & 2.48 & $L 10$ & 3.125 \\
\hline
\end{tabular}




\section{Optimization Procedure and Results}

\subsection{DGS Design and Optimization}

The basic concept of DGS is based on a so-called photonic bandgap (PBG) structure, with "defects" that are etched in the ground plane. The electromagnetic field can be controlled by using these defects, enabling circuits to become more compact [25].

Initially, the proposed ground plane in Figure $3 a$ dimensioned at $50 \times 25 \mathrm{~mm}^{2}$ $\left(0.35 \times 0.17 \mathrm{\lambda g}^{2}\right)$ is analyzed based on CMA to study the efficiency of the generated modes and to identify the dominant ones. It is known that defects in the ground plane alter the current distribution, and this feature is used to change the structure's electromagnetic characteristics. Thus, by including slots in the ground plane, additional resistances, capacitances, and inductances can be generated in any planar structure. From Figure $3 b$, it is found that only the first mode is active, as indicated by its close-to-unity modal significance. The other modes (shown from 2 to 6 ) are less important.

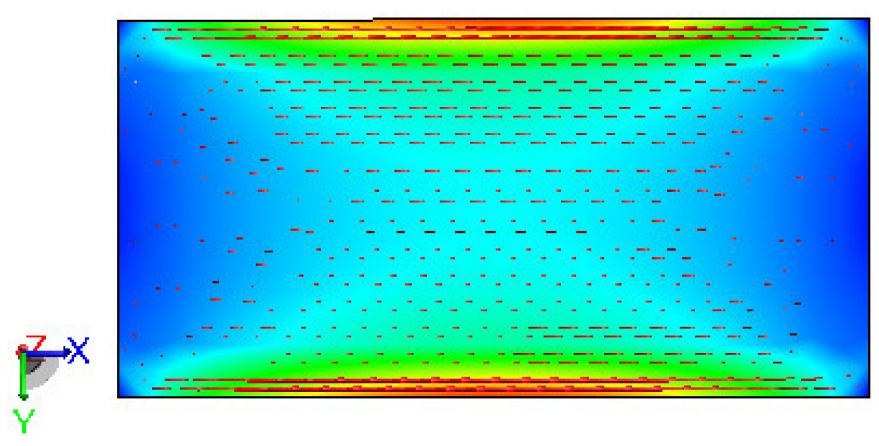

(a)

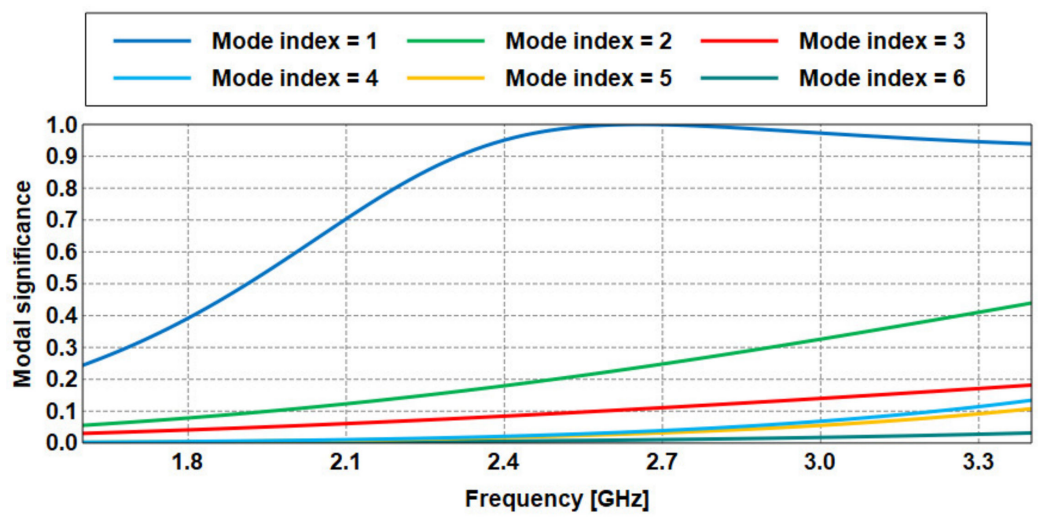

(b)

Figure 3. (a) Current distribution in the ground plane, (b) modal significance.

The next step involves shifting this main resonant mode towards the target frequency of $2.45 \mathrm{GHz}$ to ensure efficiency when this structure is being integrated with the rest of the antenna layers. The DGS structure is formed and studied gradually in several steps, as depicted in Figure 4. It is observed that the surface currents are concentrated on the upper and lower edges of the ground plane, and that high-intensity areas are created at the middle of the slot edges as the number of slots increases. At the same time, the resonant frequency of the mode decreases with the addition of slots, as shown in Figure 5, until the target $2.45 \mathrm{GHz}$ frequency is achieved. This is then set as the final DGS structure. 

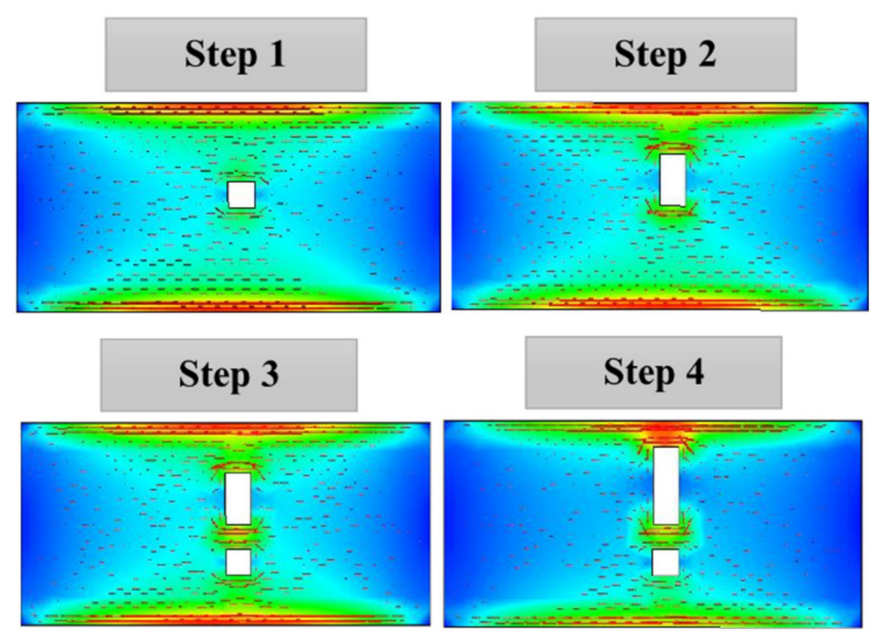

$$
\text { Step } 4
$$
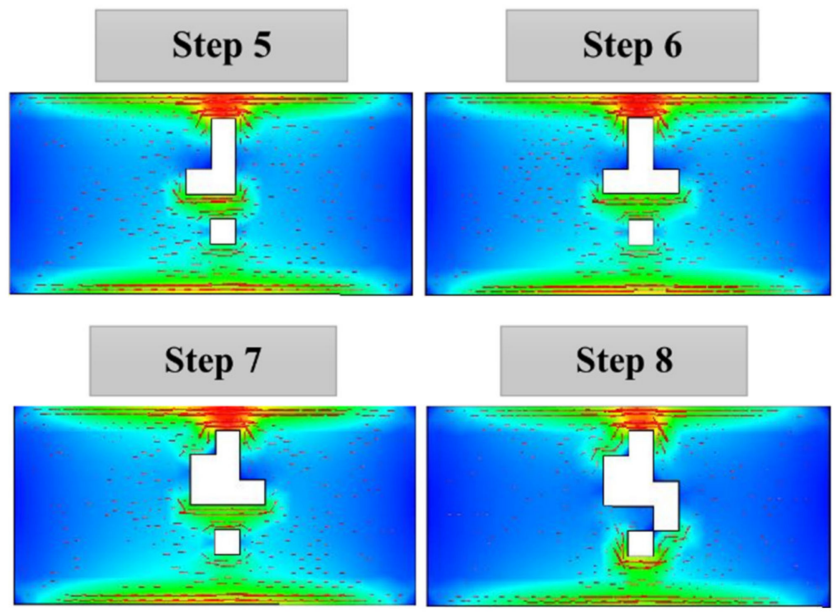

\section{Step 8}
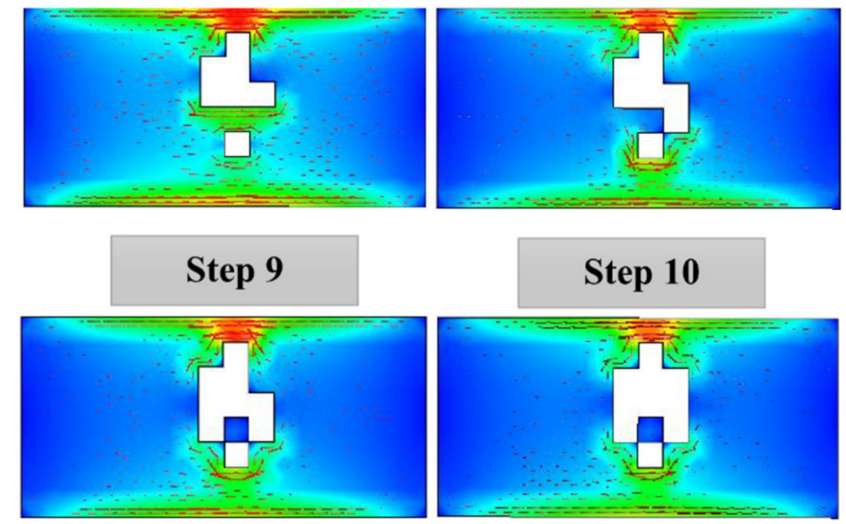

Step 10
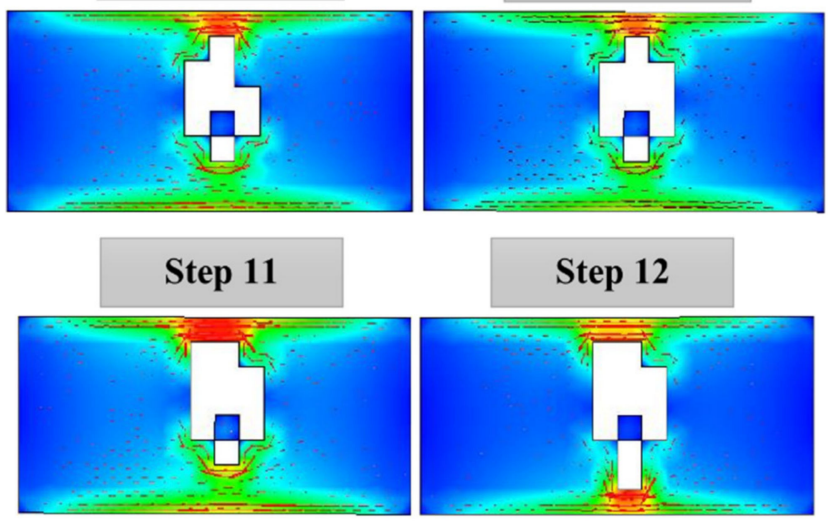

Step 12
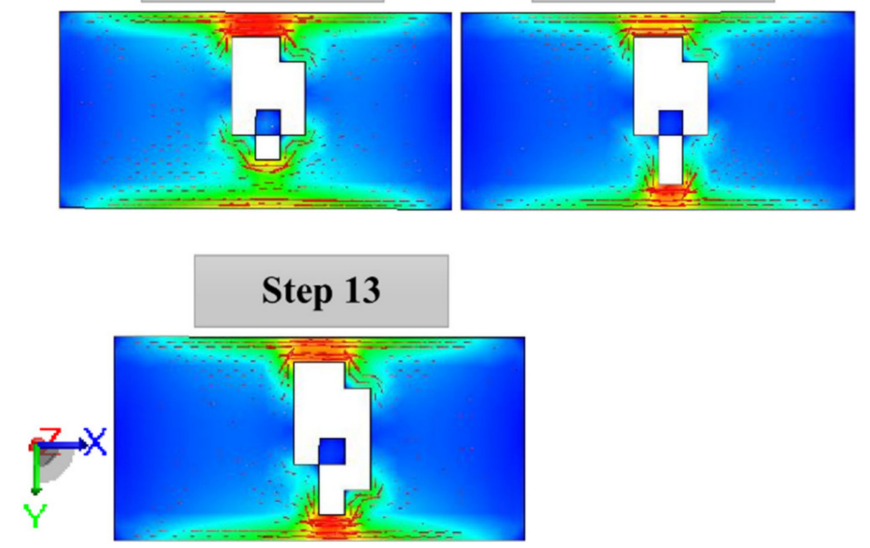

Figure 4. Surface currents in the ground plane in each step of adding slots. 


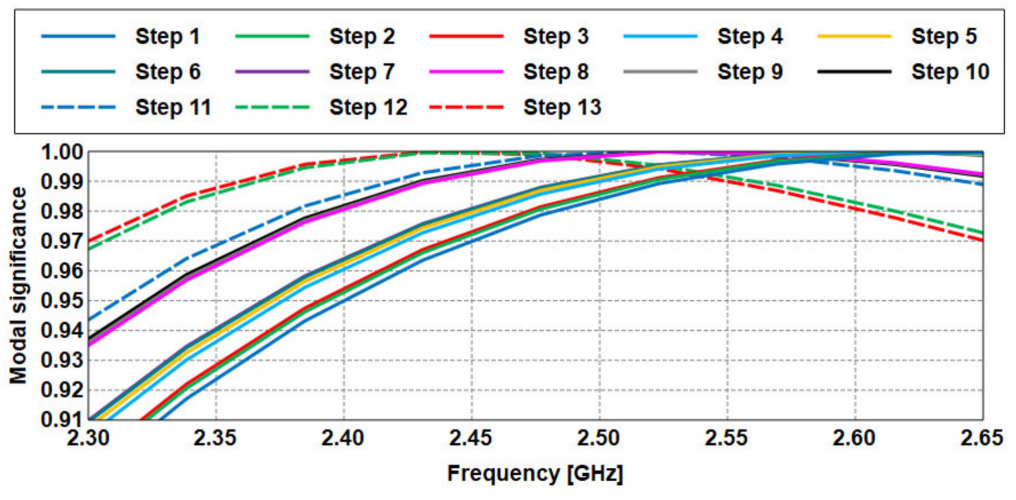

Figure 5. Modal significance of each step of slot addition.

The different design steps for the DGS from the ground plane in this work can be summarized as follows:

1. First, the PEC ground plane is analyzed alone without the rest of the antenna parts.

2. Next, the modal significance result based on the dimensions of the ground plane is assessed to identify the dominant modes and their frequencies using CMA.

3. The eigen currents are then generated on the surface of the ground plane using CMA to identify the areas having the lowest values of currents. The etching of the DGS is initialized at these locations.

4. Finally, slots are then gradually inserted until the desired resonant frequency is achieved. This is observed from the modal significance curves being significant $(>0.7)$ at the desired operating frequency. This enables the estimation of the final structure of the DGS.

Slot sizes are carefully chosen and increased gradually to avoid significant shifting in operating frequency from each step. The slot structure is not limited to a rectangular shape, and it is possible to use other geometries as well to result in DGS with different final geometries but same modal significance response.

\subsection{Patch Structure}

A conventional rectangular patch for operation at $2.45 \mathrm{GHz}$ in the given layer structure has a size in the order of $50 \times 50 \mathrm{~mm}^{2}$ [26]. Since this size is unsuitably large, our design aims at reducing these dimensions by using a diamond-shaped patch in combination with meandered rings on the two sides, yielding an RPCMR: rhombic patch with curved meandered rings.

Meandered structure is a popular technique to improve compactness. It creates longer electrical current paths inside a relatively small area. When more rings are gradually added, a more uniform current distribution throughout the overall structure is observed. After considerable computational efforts, this study resulted in an antenna with six meandered rings with a size reduction of approximately $64 \%$ compared to a conventional patch. The current distribution in each of the design steps of the RPCMR is presented in Figure 6a-f. As seen in Figure 7a, the operating frequency bands for the different steps are: $1.91-3.11 \mathrm{GHz}$ in step 1, 1.82-3.02 GHz in step 2, $1.78-2.98 \mathrm{GHz}$ in step 3, $1.76-2.93 \mathrm{GHz}$ in step 4, $1.71-2.87 \mathrm{GHz}$ in step 5 , and $1.68-2.8 \mathrm{GHz}$ in step 6 . The radiation efficiency is improved with increasing number of rings to $93 \%$ at $2.45 \mathrm{GHz}$, as shown in Figure $7 \mathrm{~b}$. 

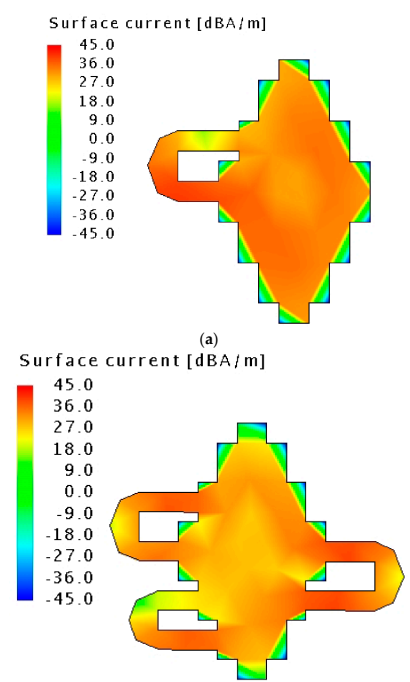

(c)

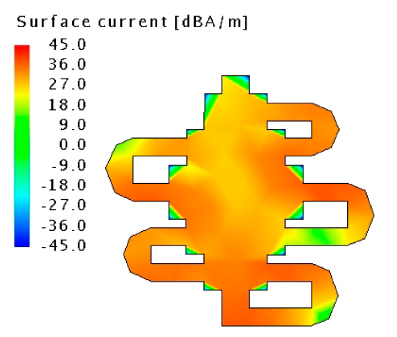

(e)

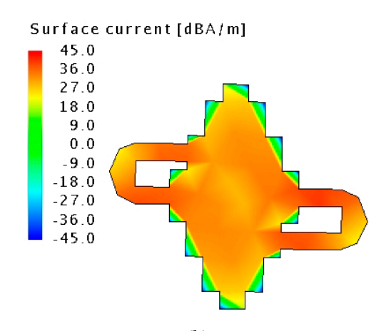

(b)

Surface current [dBA/m]

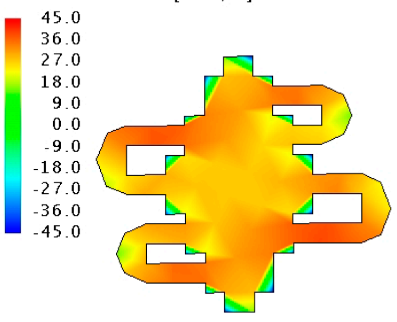

(d)

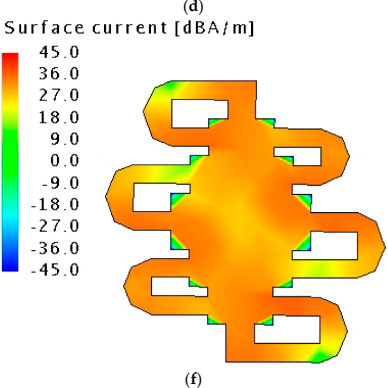

(f)

Figure 6. Surface current distribution of the fundamental CMA mode on the patch. In each step an additional meandered ring is added, as follows: (a) with one ring (b) with two rings (c) with three rings (d) with four rings (e) with five rings (f) with six rings.

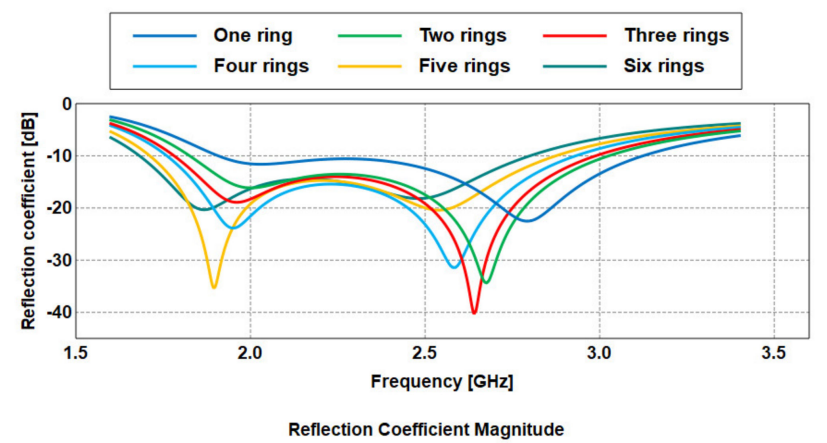

(a)

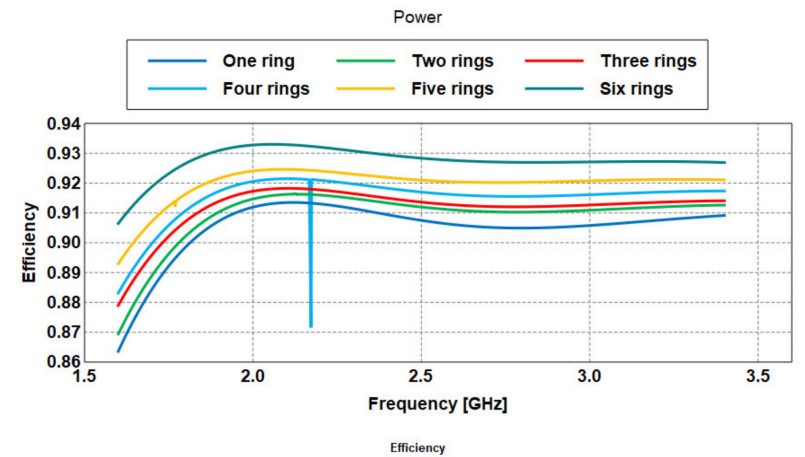

(b)

Figure 7. Simulation results from each design step: (a) reflection coefficient, (b) efficiency. 


\subsection{Optimal Ground Location}

After establishing the patch shape of the RPCMR, its location with respect to the ground needs to be optimized; see Figure 8 .

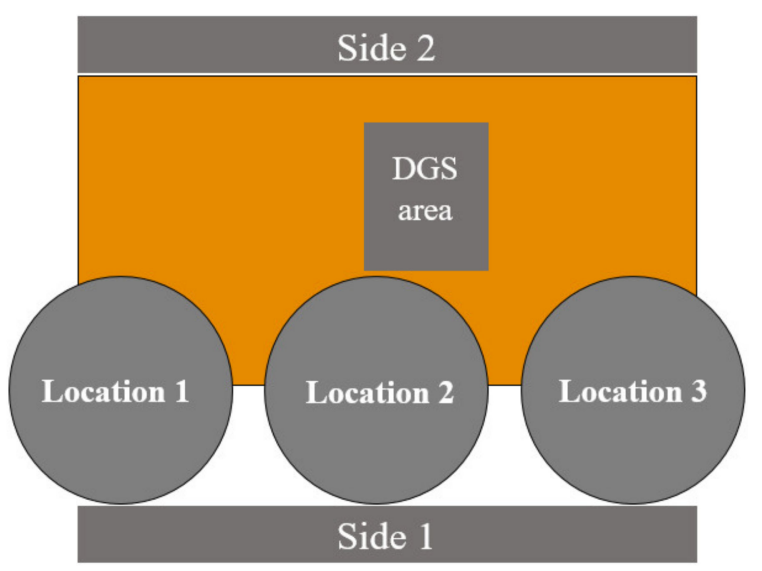

Figure 8. Different locations on the ground plane.

A thorough study was performed, pointing out that positioning the RPCMR in a corner yields the largest bandwidth. The optimum there was found based on a dimensional resolution of $0.1 \mathrm{~mm}$, both in $x$ - and $y$-direction. The reflection coefficients for two different corner locations, left at $(-19.92 \mathrm{~mm},-12.11 \mathrm{~mm})$ and right at $(19.92 \mathrm{~mm},-12.11 \mathrm{~mm})$ and the location in the center, and for grounds without and with DGS, are shown in Figure 9. For the corner locations, a dual-band behavior is obtained with a large $-10 \mathrm{~dB}$ bandwidth. For the center location, the reflection coefficient is totally unsatisfactory. Note that the coordinates are the coordinates of the center point of the patch with respect to the center of the ground. The results from placing the RPCMR on the left and right sides are not perfectly symmetrical because the antenna itself is not mirrored. It is clearly seen that the DGS technique can further improve the antenna bandwidth.

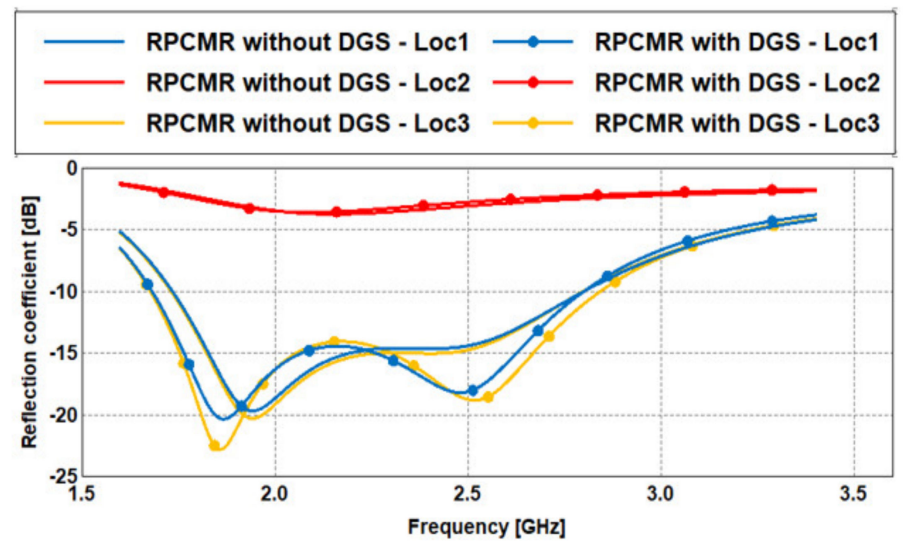

Figure 9. Reflection coefficients of the complete RPCMR antenna including substrates and feeding (at different locations).

The antenna radiation patterns in the E- and H-planes are presented in Figure 10. The antennas with and without DGS qualitatively produce the same radiation patterns. The realized gain is depicted in Figure 11. It is observed that the DGS technique slightly increases the gain in the operating band. The bandwidth and radiation efficiency at each location are summarized in Table 2. 


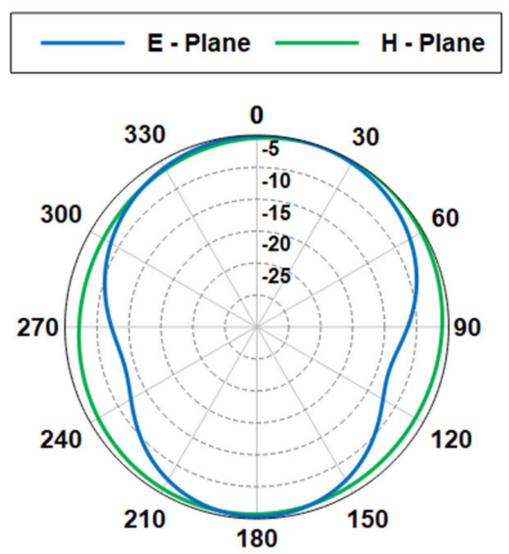

(a)

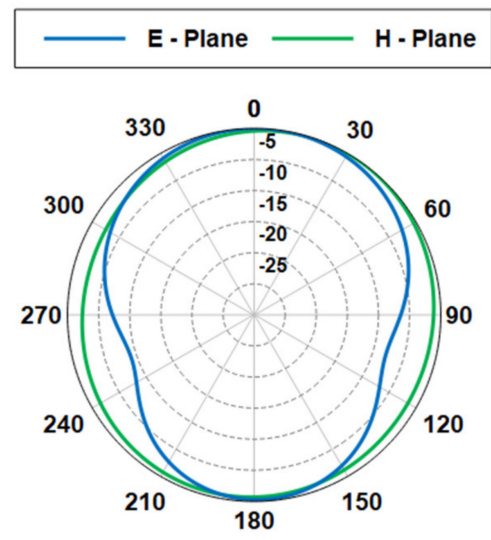

(b)

Figure 10. Normalized radiation patterns of the proposed antenna at $2.45 \mathrm{GHz}$ (E- and H-plane cuts): (a) without DGS, (b) with DGS.

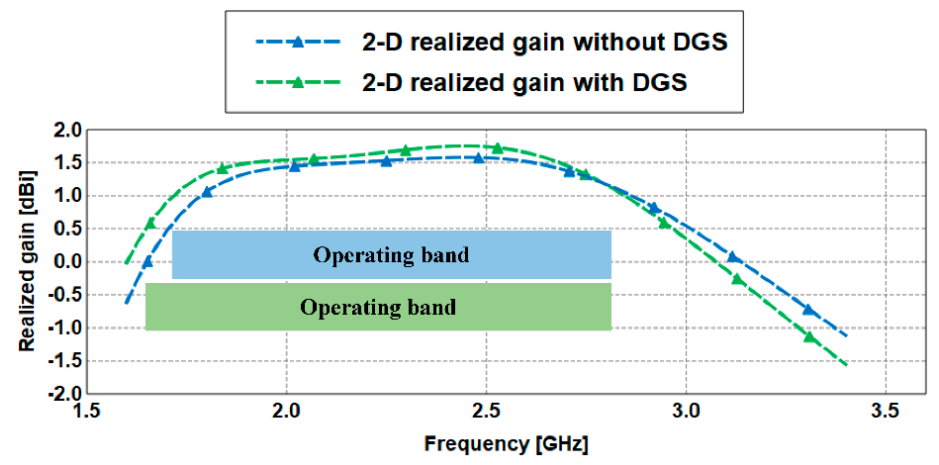

Figure 11. Realized gain of the RPCMR antenna with and without DGS.

Table 2. Reflection coefficient, realized gain, bandwidth, and efficiency.

\begin{tabular}{|c|c|c|c|c|c|c|c|c|c|c|}
\hline \multirow{2}{*}{ Location } & \multicolumn{2}{|c|}{$\begin{array}{c}\text { Resonant } \\
\text { Frequency }(\mathrm{GHz})\end{array}$} & \multicolumn{2}{|c|}{$\begin{array}{c}\text { Reflection } \\
\text { Coefficient (dB) }\end{array}$} & \multicolumn{2}{|c|}{ Realized Gain (dB) } & \multicolumn{2}{|c|}{ Bandwidth (GHz) } & \multicolumn{2}{|c|}{ Efficiency \% } \\
\hline & $\begin{array}{l}\text { Without } \\
\text { DGS }\end{array}$ & $\begin{array}{l}\text { With } \\
\text { DGS }\end{array}$ & $\begin{array}{c}\text { Without } \\
\text { DGS }\end{array}$ & $\begin{array}{l}\text { With } \\
\text { DGS }\end{array}$ & $\begin{array}{l}\text { Without } \\
\text { DGS }\end{array}$ & $\begin{array}{l}\text { With } \\
\text { DGS }\end{array}$ & $\begin{array}{c}\text { Without } \\
\text { DGS }\end{array}$ & $\begin{array}{l}\text { With } \\
\text { DGS }\end{array}$ & $\begin{array}{l}\text { Without } \\
\text { DGS }\end{array}$ & $\begin{array}{l}\text { With } \\
\text { DGS }\end{array}$ \\
\hline \multirow[t]{2}{*}{1} & 1.95 & 1.87 & -19.66 & -20.34 & 2.5 & 2.5 & \multirow{2}{*}{1.066} & \multirow{2}{*}{1.118} & 92 & 93 \\
\hline & 2.45 & 2.45 & -14.59 & -18.09 & 4.0 & 3.0 & & & 93 & 93 \\
\hline 2 & & & & & & & & & & \\
\hline \multirow{2}{*}{3} & 1.94 & 1.86 & -20.26 & -22.8 & 2.5 & 3 & \multirow{2}{*}{1.068} & \multirow{2}{*}{1.166} & 92 & 92 \\
\hline & 2.4 & 2.5 & -15.03 & -18.74 & 4 & 3 & & & 93 & 92 \\
\hline
\end{tabular}




\section{Antenna on Body Evaluation}

In this work, a heterogeneous model is used to represent the human body. It consists of four layers of tissue-skin, fat, muscle, and bone, as shown in Figure 12 [27-29].

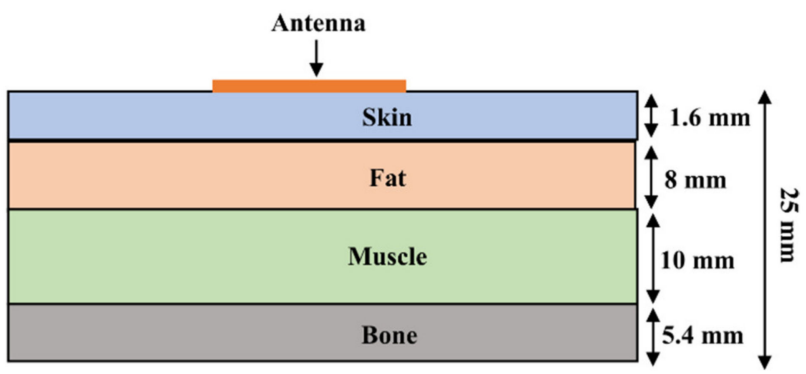

Figure 12. Side view of the heterogeneous model.

To assess the antenna performance when placed on-body $(\mathrm{OB})$, the antenna is placed at distances of $10 \mathrm{~mm}, 6 \mathrm{~mm}$, and $2 \mathrm{~mm}$ from the human model. Such spacing mimics the natural spacing between the antenna and body due to clothing. The reflection coefficients when placed on-body shown in Figure 13 indicate that the antenna is operational across a much wider frequency band. For instance, the antenna operates from $1.706 \mathrm{GHz}$ to $2.844 \mathrm{GHz}(1.138 \mathrm{GHz}$ of bandwidth) when placed at $10 \mathrm{~mm}$.

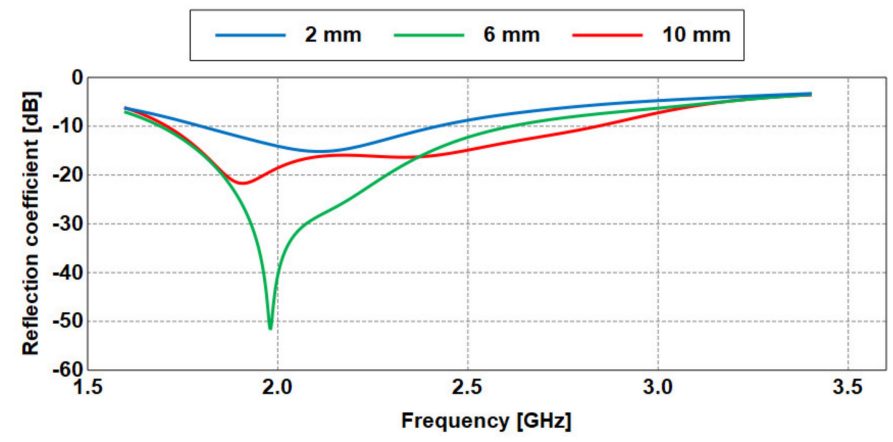

Figure 13. Simulated reflection coefficient of the antenna placed on body with different spacings.

This $10 \mathrm{~dB}$ impedance bandwidth is significantly decreased to $0.92 \mathrm{GHz}$ (from $1.69 \mathrm{GHz}$ to $2.61 \mathrm{GHz}$ ) and $0.62 \mathrm{GHz}$ (from $1.79 \mathrm{GHz}$ to $2.41 \mathrm{GHz}$ ) when the spacing is reduced to $6 \mathrm{~mm}$ and $2 \mathrm{~mm}$, respectively, due to coupling to the human body. Thus, the bandwidth decreases when the distance between the antenna and the heterogeneous model is reduced.

The specific absorption rate (SAR) [30] is defined as electromagnetic energy absorbed per unit biological human tissue mass when exposed to a radiating device. SAR values are usually averaged over a certain volume of exposed biological tissue (typically $1 \mathrm{~g}$ or $10 \mathrm{~g}$ ). Figure 14 presents the SAR levels obtained for the antenna placed on the heterogeneous model. Values within the standard limits are obtained as illustrated in Table 3.

Table 3. Simulated SAR Values.

\begin{tabular}{ccccc}
\hline & \multicolumn{3}{c}{ SAR Values (W/kg) } \\
\cline { 2 - 5 } Distance (mm) & \multicolumn{2}{c}{$\mathbf{1} \mathbf{~ g ~ C u b e}$} & \multicolumn{2}{c}{$\mathbf{1 0}$ g Cube } \\
\cline { 2 - 5 } & $\mathbf{1 . 8 7} \mathbf{~ G H z}$ & $\mathbf{2 . 4 5 ~ G H z}$ & $\mathbf{1 . 8 7 ~ G H z}$ & $\mathbf{2 . 4 5 ~ G H z}$ \\
\hline $10 \mathrm{~mm}$ & 0.115 & 0.093 & 0.122 & 0.111 \\
$6 \mathbf{m m}$ & 0.139 & 0.172 & 0.130 & 0.124 \\
$2 \mathrm{~mm}$ & 0.253 & 0.210 & 0.163 & 0.157 \\
\hline
\end{tabular}




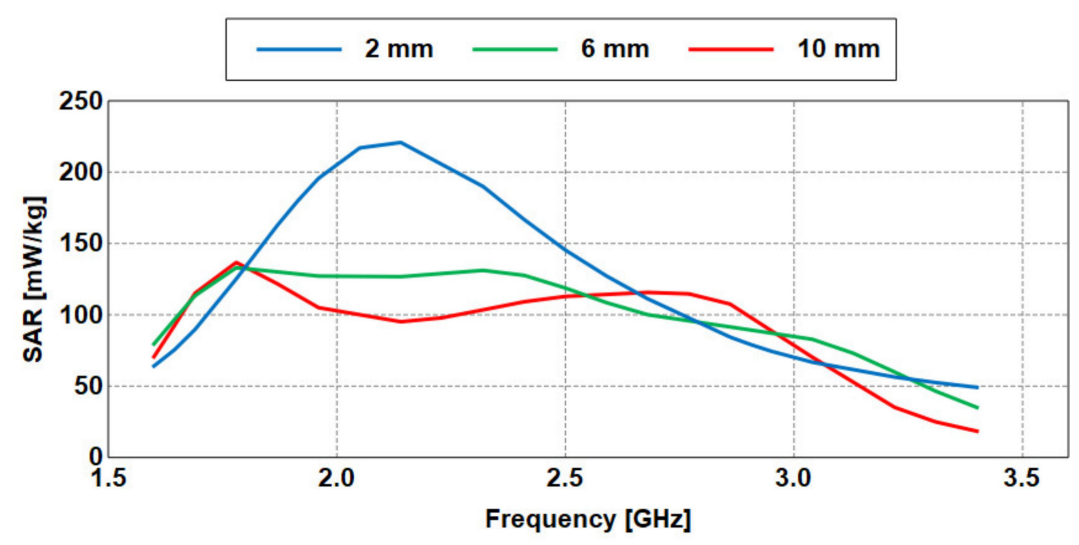

(a)

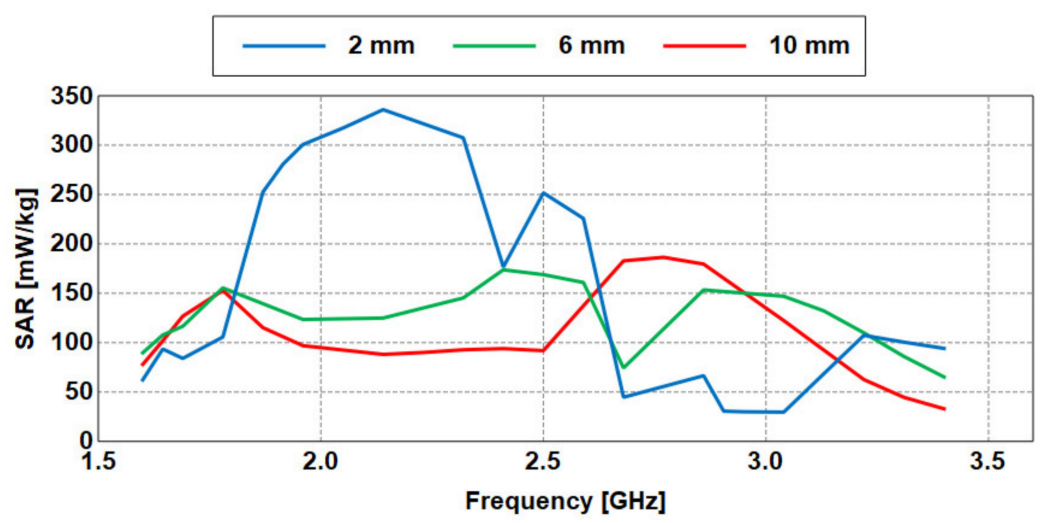

(b)

Figure 14. Maximum SAR values for the antenna on body for different distances: (a) $1 \mathrm{~g}$, (b) $10 \mathrm{~g}$.

Another aspect when the antenna is placed close to the body is the reduction of the back radiation; see Figure 15. In general, the radiation performance to the front then is improved. In our case, the front-to-back ration (FBR) increases to $10.94 \mathrm{~dB}$ at $2.45 \mathrm{GHz}$ for a spacing of $10 \mathrm{~mm}$.

Further, the antenna gain is reduced compared to free space due to the absorption by the human tissue; see Table 4.

Table 4. Simulated realized gain results at $\theta=0^{\circ}$.

\begin{tabular}{ccc}
\hline \multirow{2}{*}{ Distance $(\mathbf{m m})$} & \multicolumn{2}{c}{ Realized Gain (dBi) } \\
\cline { 2 - 3 } & $\mathbf{1 . 8 7} \mathbf{~ G H z}$ & $\mathbf{2 . 4 5} \mathbf{G H z}$ \\
\hline Free space & 1.46 & 1.75 \\
$10 \mathrm{~mm}$ & -1.75 & -1.44 \\
$6 \mathrm{~mm}$ & -3.81 & -3.72 \\
$2 \mathrm{~mm}$ & -7.18 & -7.05 \\
\hline
\end{tabular}




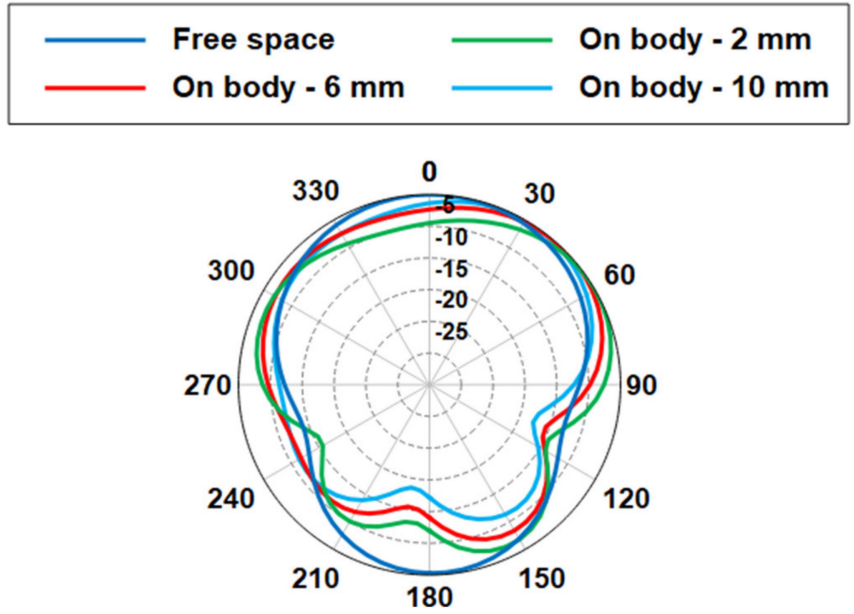

(a)
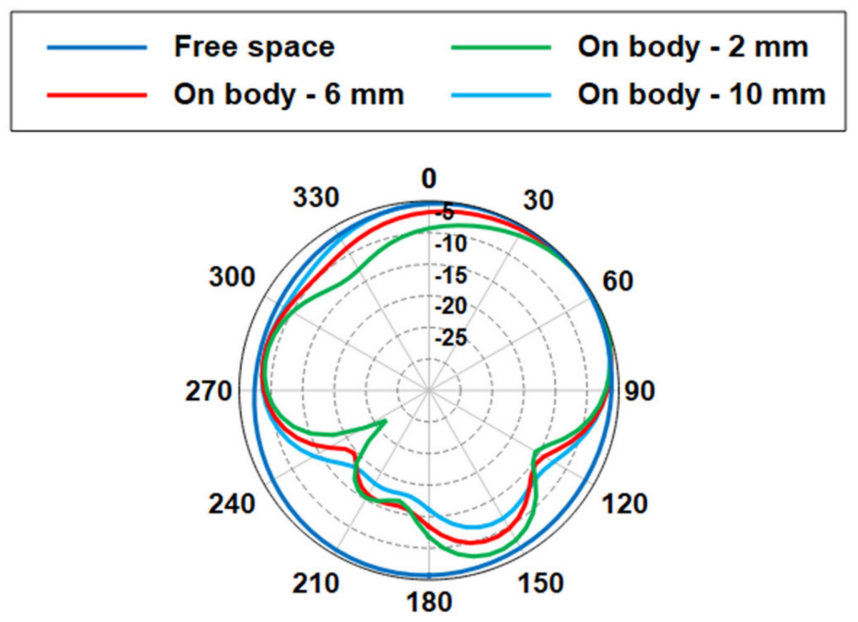

(b)

Figure 15. Normalized radiation patterns of the antenna when placed on body for different spacings: (a) E-plane cut, (b) H-plane cut.

\section{Prototype and Measurements}

A prototype of the proposed antenna was fabricated, using manual cutting tools, and evaluated experimentally. The measured reflection coefficient in Figure 16 indicates a $-10 \mathrm{~dB}$ reflection bandwidth of around $860 \mathrm{MHz}$ (from 1.72 to $2.58 \mathrm{GHz}$ ). When evaluated on the chest with $10 \mathrm{~mm}$ between the antenna and the human body, no huge changes are seen in the upper part of the operating frequency band. However, the lower resonant frequency shifts down and deteriorates. Figure 17 compares the simulated and measured radiation patterns. In general, there is an acceptable agreement between simulated and measured patterns. Table 5 summarizes all results.

The flexible characteristic of the proposed antennas is further studied by bending the antenna as shown in Figure 18 at different angles $\left(40^{\circ}, 30^{\circ}, 20^{\circ}\right.$, and $10^{\circ}$ from the least to the worst degree of bending). The measured reflection coefficient when the antenna is bent at $40^{\circ}$ is $-14.94 \mathrm{~dB}$ at $2.41 \mathrm{GHz}$. An overall bandwidth of $1032 \mathrm{MHz}$ is achieved. Next, by increasing the bending angle to $30^{\circ}$ and $20^{\circ}$, the operating frequency of the antenna slightly decreases to $2.4 \mathrm{GHz}$ and $2.39 \mathrm{GHz}$, with a reflection coefficient of $-13.51 \mathrm{~dB}$ and $-13.77 \mathrm{~dB}$, respectively. The bandwidth produced from these two configurations are $986 \mathrm{MHz}$ and $979 \mathrm{MHz}$, respectively. Finally, the most extreme bending angle of $10^{\circ}$ further shifts the resonant frequency to $2.38 \mathrm{GHz}$, with $-11.38 \mathrm{~dB}$ of reflection coefficient and the smallest impedance bandwidth of $448 \mathrm{MHz}$. The increase in bending (reduction in bending angle) reduces the antenna bandwidth with a slight decrease in the operating 
frequency. This is due to the variation of the effective length as the bending increases [VIII], and is evident from Table 6 . The gradually bent antenna (from the flat case to $40^{\circ}, 30^{\circ}$, $20^{\circ}$, and $10^{\circ}$ ) increases the effective length of the RPCMA radiator at the long edge of the chassis (along the y-direction). Besides this, when the proposed antenna is placed at a distance of $5 \mathrm{~mm}$ from the forearm, two resonant bands are obtained centered at $1.85 \mathrm{GHz}$ and $2.52 \mathrm{GHz}$, with a bandwidth of $249 \mathrm{MHz}$ and $487 \mathrm{MHz}$, respectively. The reflection coefficients for the bending investigation are presented in Figure 19 and summarized in Table 6.

Table 5. Simulated and measured performance of the proposed antenna.

\begin{tabular}{|c|c|c|c|c|}
\hline \multicolumn{2}{|c|}{ Results } & \multirow{2}{*}{$\begin{array}{c}\text { Resonant Frequency (GHz) } \\
1.87 / 2.45\end{array}$} & \multirow{2}{*}{$\begin{array}{c}\text { Reflection Coefficient (dB) } \\
-20.34 /-18.09\end{array}$} & \multirow{2}{*}{$\frac{\text { Bandwidth \%/(MHz) }}{49.04 / 1118}$} \\
\hline & FS & & & \\
\hline Sim. & $\mathrm{OB}$ & 1.9 & -21.71 & $49.74 / 1131$ \\
\hline \multirow{2}{*}{ Meas. } & FS & $1.8 / 2.38$ & $-10.33 /-11.82$ & $40.16 / 864$ \\
\hline & $\mathrm{OB}$ & 2.44 & -13.09 & $11.44 / 281$ \\
\hline
\end{tabular}

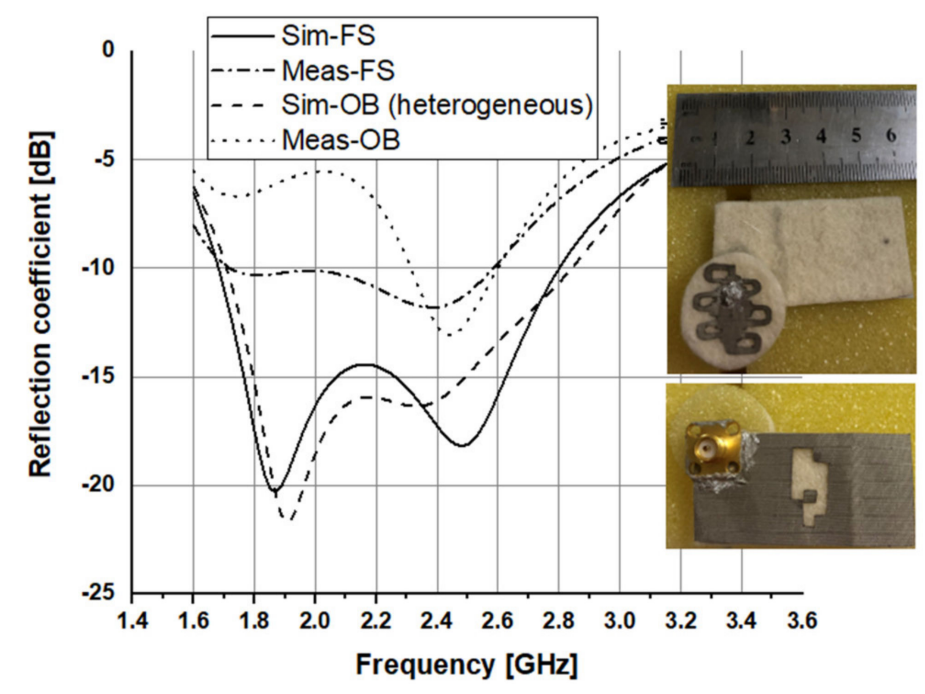

Figure 16. Simulated and measured reflection coefficients at $2.45 \mathrm{GHz}$.

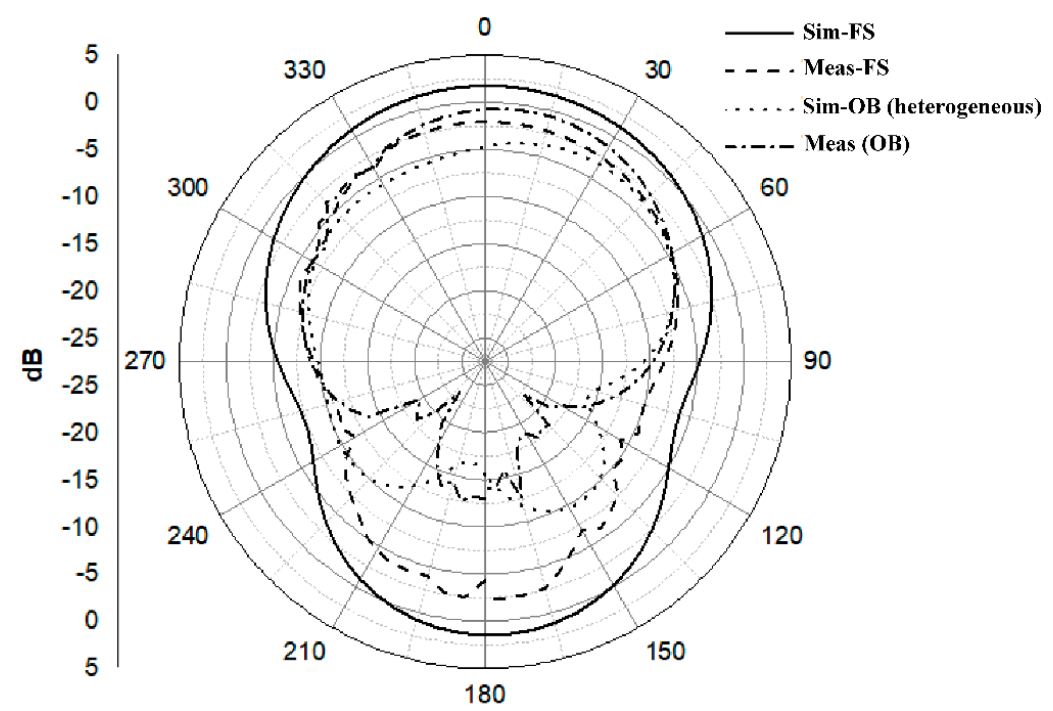

Figure 17. Simulated and measured radiation patterns at $2.45 \mathrm{GHz}$. 


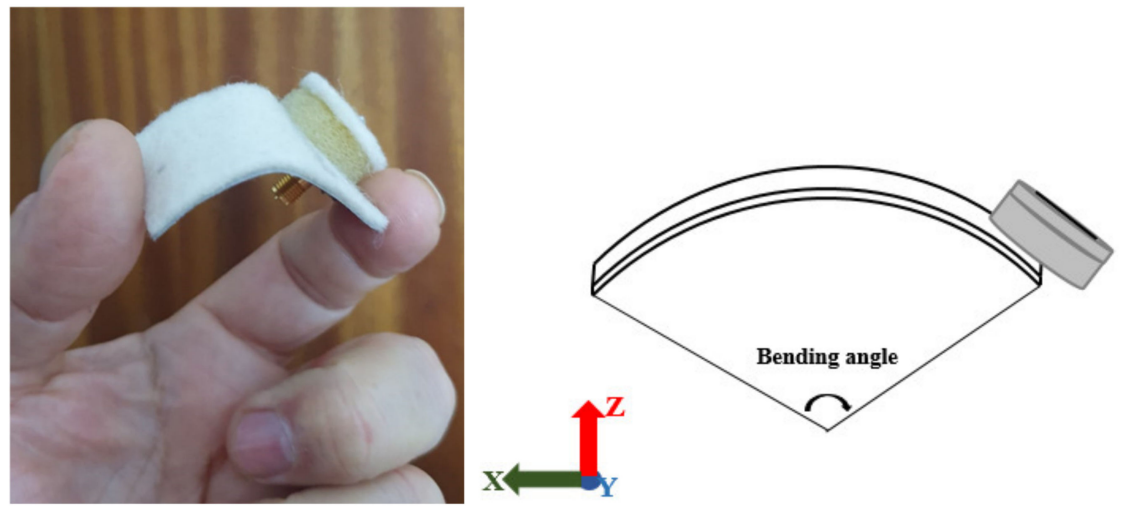

Figure 18. Photograph of the RPCMR antenna when bent.

Table 6. Experimental results of the RPCMR antenna when bent at different angles and when placed on the forearm.

\begin{tabular}{cccc}
\hline Case & Operating Frequency $\mathbf{( G H z )}$ & Reflection Coefficient (dB) & Bandwidth $(\mathbf{M H z})$ \\
\hline Bent at $10^{\circ}$ & 2.38 & -11.38 & 448 \\
Bent at $20^{\circ}$ & 2.39 & -13.77 & 979 \\
Bent at $30^{\circ}$ & 2.4 & -13.51 & 986 \\
Bent at $40^{\circ}$ & 2.41 & -14.94 & 1032 \\
Bent on forearm & 1.85 & -12.27 & 249 \\
\hline
\end{tabular}

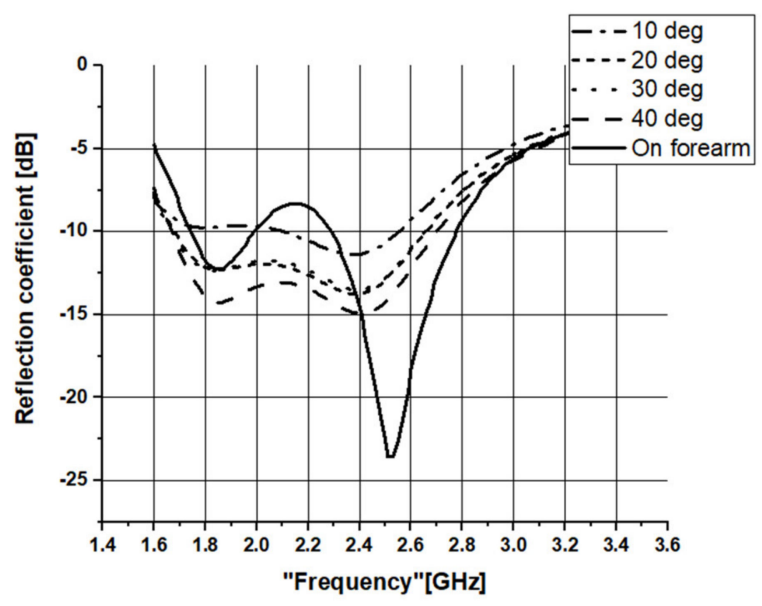

Figure 19. Reflection coefficients of the RPCMR antenna when bent at different angles and when placed on the forearm.

The performance of the proposed antenna is compared with other state-of-the-art wireless body area network (WBAN) antennas designed for operation in the same frequency band in Table 7. The proposed antenna features the largest bandwidth and improved efficiency compared to literature. Moreover, the operating bandwidth is improved compared to other flexible antennas in [22,31-35]. Its compact size of $0.35 \times 0.17 \mathrm{\lambda g}^{2}$ also makes the proposed antenna among the smallest available wideband antennas, enabling its easy integration into wearable systems. Finally, the proposed antenna also provides a higher gain compared to [35] and enhanced radiation efficiency relative to the antennas in $[22,31-33]$. 
Table 7. Comparison of the proposed antenna with other wideband textile-band antennas available in literature.

\begin{tabular}{|c|c|c|c|c|c|c|}
\hline Ref & $\begin{array}{c}\text { Antenna Dimensions } \\
\left(\lambda \mathrm{g}^{2} / \mathrm{mm}^{2}\right)\end{array}$ & $\begin{array}{l}\text { Operating Frequency } \\
\text { (GHz) }\end{array}$ & Bandwidth (\%) & Gain (dBi) & Flexible? & Efficiency \% \\
\hline [31] & $\begin{array}{c}\text { Radius }=0.26 / \\
25\end{array}$ & $2.45 / 5.8$ & $\begin{array}{c}10.9 \\
\text { (Meas) }\end{array}$ & $\begin{array}{c}-5.1(2.45 \mathrm{GHz}) \\
3.3(5.8 \mathrm{GHz}) \\
(\mathrm{Mea})\end{array}$ & Yes & $\begin{array}{c}16(2.45 \mathrm{GHz}) \\
54(5.8 \mathrm{GHz}) \\
(\mathrm{Sim}) \\
74-90(\mathrm{Sim})\end{array}$ \\
\hline [32] & $\begin{array}{l}0.63 \times 0.57 / \\
\quad 60 \times 55\end{array}$ & 2.45 & $\begin{array}{l}12.88 \\
(\mathrm{Sim})\end{array}$ & Not reported & Yes & $\begin{array}{c}\text { Over the entire } \\
\text { operating } \\
\text { bandwidth region }\end{array}$ \\
\hline [22] & $\begin{array}{c}0.84 \times 0.42 / \\
50 \times 25\end{array}$ & 2.45 & 34.39 (Sim) & $5.2(\mathrm{Sim})$ & Yes & 72.1 (Sim) \\
\hline [33] & $\begin{array}{l}0.77 \times 0.58 / \\
80 \times 60\end{array}$ & 2.45 & 12.8 (Sim) & 6.07 (Sim) & Yes & 59 (Sim) \\
\hline [34] & $\begin{array}{c}0.57 \times 0.49 / \\
53.6 \times 45.8 \\
\text { (of the patch) }\end{array}$ & 2.45 & 6.1 (Meas) & 7.8 (Meas) & Yes & 90 (Meas) \\
\hline [35] & $\begin{array}{c}0.51 \times 0.91 / \\
50 \times 19 \\
\text { (PIFA antenna) }\end{array}$ & $\begin{array}{c}2.45(\mathrm{Sim}) \\
2.63 \text { (Meas) }\end{array}$ & $\begin{array}{c}28(\text { Sim) } \\
31 \text { (Meas) }\end{array}$ & $\begin{array}{l}1.78(\mathrm{Sim}) \\
1.2 \text { (Meas) }\end{array}$ & Yes & N/A \\
\hline This work & $\begin{array}{l}0.35 \times 0.17 / \\
50 \times 25\end{array}$ & $\begin{array}{c}1.87 / 2.45 \\
(\text { Sim) } \\
1.8 / 2.38 \\
\text { (Meas) }\end{array}$ & $\begin{array}{c}49.04 \text { (Sim) } \\
40.16 \text { (Meas) }\end{array}$ & $\begin{array}{c}2.5(1.87 \mathrm{GHz}) \\
3(2.45 \mathrm{GHz}) \\
(\mathrm{Sim})\end{array}$ & Yes & $\begin{array}{c}93(1.87 \mathrm{GHz}) \\
93(2.45 \mathrm{GHz}) \\
\text { (Sim) }\end{array}$ \\
\hline
\end{tabular}

$\lambda \mathrm{g}=$ lower operating wavelength, $\operatorname{Sim}=$ simulated, Meas = measured.

\section{Conclusions}

In this paper, a compact dual-band RPCMR antenna for on-body applications was proposed, designed, prototyped, and measured. The characteristic mode analysis was used to optimize the use of a defected ground structure in order to maximize the bandwidth. The method of analysis (CMA) proposed in this study is appropriate to be used in evaluating antennas made using different flexible or nonflexible materials. This is because the initial simulations in the CMA method proposed do not account for the substrate and excitation. Instead, this method only accounts for the metallic parts of the antenna, regardless of whether it is flexible or not. This, then, reduces the required time and effort in the optimization, besides simplifying the design procedure. This resulted in a fractional bandwidth of $49.04 \%$, a gain of $3 \mathrm{dBi}$, and an average efficiency of $93 \%$. Moreover, the antenna is compact in size $\left(0.35 \times 0.17 \lambda \mathrm{g}^{2}\right)$, lightweight, and flexible, which makes it a prospective candidate for WBAN applications.

Author Contributions: Conceptualization, B.B.Q.E. and P.J.S.; methodology, B.B.Q.E., P.J.S. and A.A.A.-H.; validation, B.B.Q.E., P.J.S., A.A.A.-H. and G.A.E.V.; investigation, B.B.Q.E.; resources, P.A.; writing—original draft preparation, B.B.Q.E.; writing—review and editing, P.J.S. and G.A.E.V.; visualization, P.A. and G.A.E.V.; supervision, P.J.S. and A.A.A.-H.; project administration, P.J.S. and P.A.; funding acquisition, P.J.S. and P.A. All authors have read and agreed to the published version of the manuscript.

Funding: This research was funded by Malaysia Ministry of Higher Education, grant number FRGS/1/2020/TK0/UNIMAP/02/19, and King Mongkut's University of Technology North Bangkok, grant no KMUTNB-64-KNOW-46. The APC was funded by KMUTNB.

Institutional Review Board Statement: Not applicable.

Informed Consent Statement: Not applicable.

Conflicts of Interest: The authors declare no conflict of interest. 


\section{References}

1. Sabban, A. Small New Wearable Antennas for IOT, Medical and Sport Applications. In Proceedings of the 2019 13 th European Conference on Antennas and Propagation (EuCAP), Krakow, Poland, 31 March-5 April 2019; pp. 1-5.

2. Li, S.; Li, J. Smart Patch Wearable Antenna on Jeans Textile for Body Wireless Communication. In Proceedings of the 201812 th International Symposium on Antennas, Propagation and EM Theory (ISAPE), Hangzhou, China, 3-6 December 2018; pp. 1-4. [CrossRef]

3. Alsharif, F.; Kurnaz, C. Wearable Microstrip Patch Ultra-Wide Band Antenna for Breast Cancer Detection. In Proceedings of the 2018 41st International Conference on Telecommunications and Signal Processing (TSP), Athens, Greece, 4-6 July 2018; pp. 1-5. [CrossRef]

4. Almangour, Y.; Sabouni, A. Flexible Antenna for Wearable Devices at Wi-Fi frequency band. In Proceedings of the 2018 International Applied Computational Electromagnetics Society Symposium—China (ACES), Beijing, China, 29 July-1 August 2018; pp. 1-2. [CrossRef]

5. Yan, S.; Volskiy, V.; Vandenbosch, G.A.E. Compact Dual-Band Textile PIFA for 433-MHz/2.4-GHz ISM Bands. IEEE Antennas Wirel. Propag. Lett. 2017, 16, 2436-2439. [CrossRef]

6. Agneessens, S.; Rogier, H. Compact Half Diamond Dual-Band Textile HMSIW On-Body Antenna. IEEE Trans. Antennas Propag. 2014, 62, 2374-2381. [CrossRef]

7. Yan, S.; Soh, P.J.; Vandenbosch, G.A.E. Compact All-Textile Dual-Band Antenna Loaded with Metamaterial-Inspired Structure. IEEE Antennas Wirel. Propag. Lett. 2015, 14, 1486-1489. [CrossRef]

8. Yan, S.; Soh, P.J.; Vandenbosch, G.A.E. Wearable Dual-Band Magneto-Electric Dipole Antenna for WBAN/WLAN Applications. IEEE Trans. Antennas Propag. 2015, 63, 4165-4169. [CrossRef]

9. Sanz-Izquierdo, B.; Batchelor, J.C.; Sobhy, M.I. Button Antenna on Textiles for Wireless Local Area Network on Body Applications. IET Microw. Antennas Propag. 2010, 4, 1980-1987. [CrossRef]

10. Yang, X.; Liu, Y.; Gong, S. Design of a Wideband Omnidirectional Antenna with Characteristic Mode Analysis. IEEE Antennas Wirel. Propag. Lett. 2018, 17, 993-997. [CrossRef]

11. Bauer, J.E.; Gentner, P.K. Characteristic Mode Analysis of a Circular Polarised Rectangular Patch Antenna. In Proceedings of the 2019 13th European Conference on Antennas and Propagation (EuCAP), Krakow, Poland, 29 July-1 August 2019 ; pp. 1-3.

12. Mahlaoui, Z.; Antonino-Daviu, E.; Latif, A.; Ferrando-Bataller, M. From the Characteristic Modes Analysis to the Design of a Radiation Pattern Reconfigurable Antenna. In Proceedings of the 2019 13th European Conference on Antennas and Propagation (EuCAP), Krakow, Poland, 29 July-1 August 2019; pp. 1-4.

13. Phung, Q.Q.; Nguyen, T.H.; Michishita, N.; Sato, H.; Koyanagi, Y.; Morishita, H. Characteristic Mode Analysis of U-Shaped Folded Dipole Antenna for WiMAX. In Proceedings of the 2019 International Workshop on Antenna Technology (iWAT), Miami, FL, USA, 3-6 March 2019; pp. 105-107. [CrossRef]

14. Garbacz, R.; Turpin, R. A Generalized Expansion for Radiated and Scattered Fields. IEEE Trans. Antennas Propag. 1971, 19, 348-358. [CrossRef]

15. Harrington, R.; Mautz, J. Computation of Characteristic Modes for Conducting Bodies. IEEE Trans. Antennas Propag. 1971, 19, 629-639. [CrossRef]

16. Harrington, R.; Mautz, J. Theory of Characteristic Modes for Conducting Bodies. IEEE Trans. Antennas Propag. 1971, 19, 622-628. [CrossRef]

17. Dixit, M.; Tripathi, M.G.S. CPW-fed Monopole Printed Antenna using Staircase shaped Defected Ground Structure for Wireless Application. In Proceedings of the 2018 IEEE International Students' Conference on Electrical, Electronics and Computer Science (SCEECS), Bhopal, India, 24-25 February 2018; pp. 1-4. [CrossRef]

18. Ma, W. A Microstrip Patch Antenna Design with Harmonic Rejection Using Defected Ground Structure. In Proceedings of the 2019 IEEE MTT-S International Wireless Symposium (IWS), Guangzhou, China, 19-22 May 2019; pp. 1-3. [CrossRef]

19. Ponchak, G.E. Dual of Defected Ground Structure for Coplanar Stripline. IEEE Microw. Wirel. Compon. Lett. 2018, 28, 105-107. [CrossRef]

20. Islam, M.S.; Ibrahimy, M.I.; Motakabber, S.M.A.; Hossain, A.K.M.Z. A Rectangular Inset-Fed Patch Antenna with Defected Ground Structure for ISM Band. In Proceedings of the 2018 7th International Conference on Computer and Communication Engineering (ICCCE), Kuala Lumpur, Malaysia, 19-20 September 2018; pp. 104-108. [CrossRef]

21. Guha, D.; Biswas, S.; Kumar, C. Printed Antenna Designs Using Defected Ground Structures: A Review of Fundamentals and State-of-the-Art Developments. Forum Electromagn. Res. Methods Appl. Technol. (FERMAT) 2014, 2, 1-13.

22. Yan, S.; Vandenbosch, G.A.E. Design of Wideband Wearable Antenna using Characteristic Mode Analysis. In Proceedings of the 2019 URSI Asia-Pacific Radio Science Conference (AP-RASC), New Delhi, India, 9-15 March 2019; pp. 1-4. [CrossRef]

23. Zaidi, N.I.; Ali, M.T.; Rahman, N.H.A.; Nordin, M.S.A.; Shah, A.A.S.A.; Yahya, M.F.; Yon, H. Analysis of Different Feeding Techniques on Textile Antenna. In Proceedings of the 2019 International Symposium on Antennas and Propagation (ISAP), Xi'an, China, 27-30 October 2019; pp. 1-3.

24. Cibin, C.; Leuchtmann, P.; Gimersky, M.; Vahldieck, R.; Moscibroda, S. Modified E-shaped PIFA antenna for wearable systems. In Proceedings of the 2004 URSI International Symposium on Electromagnetic Theory (EMTS), Pisa, Italy, 23-27 May 2004.

25. Rahman, M.M.; Islam, M.S.; Wong, H.Y.; Alam, T.; Islam, M.T. Performance Analysis of a Defected Ground-Structured Antenna Loaded with Stub-Slot for 5G Communication. J. Sci. Technol. Sens. Biosens. 2019, 19, 2634. [CrossRef] [PubMed] 
26. Alayesh, M.A. Analysis and Design of Reconfigurable Multi-Band Stacked Microstrip Patch Antennas (MSAs) for Wireless Applications. In Electrical \& Computer Engineering Department; The University of New Mexico: Albuquerque, NM, USA, 2007.

27. Kaschel, H.; Ahumada, C. Design of Rectangular Microstrip Patch Antenna for $2.4 \mathrm{GHz}$ applied a WBAN. In Proceedings of the IEEE International Conference on Automation/XXIII Congress of the Chilean Association of Automatic Control (ICA-ACCA), Concepcion, Chile, 17-19 October 2018; pp. 1-6. [CrossRef]

28. Miralles, E.; Andreu, C.; Cabedo-Fabrés, M.; Ferrando-Bataller, M.; Monserrat, J. UWB On-Body Slotted Patch Antennas for In-Body Communications. In Proceedings of the 11th European Conference on Antennas and Propagation (EUCAP), Paris, France, 19-24 March 2017. [CrossRef]

29. Gupta, A.; Kansal, A.; Chawla, P. Design of a Compact Dual-Band Antenna for On-/Off Body Communication. IETE J. Res. 2020, 1-9. [CrossRef]

30. Carcamo, H.K.; Olivares, C.L.; Vera, C.A. Numerical Finite Difference Method of Electric Field Generated to determine the SAR Generated in a Microstrip Antenna Type Applied to a WBAN. IEEE Lat. Am. Trans. 2016, 14, 2921-2926. [CrossRef]

31. Bhattacharjee, S.; Maity, S.; Chaudhuri, S.R.B.; Mitra, M. A Compact Dual-Band Dual-Polarized Omnidirectional Antenna for On-Body Applications. IEEE Trans. Antennas Propag. 2019, 67, 5044-5053. [CrossRef]

32. Bhattacharjee, S.; Midya, M.; Chaudhuri, S.R.B.; Mitra, M. A Ground Radiating Antenna for On-Body Communication. In Proceedings of the IEEE Applied Electromagnetics Conference (AEMC), Miami, Aurangabad, India, 19-22 December 2017. [CrossRef]

33. Suraya, A.N.; Sabapathy, T.; Jusoh, M.; Ghazali, N.H.; Osman, M.N.; Ismail, S.; Awal, M.R. Wearable Antenna Gain Enhancement Using Reactive Impedance Substrate. Indones. J. Electr. Eng. Comput. Sci. 2019, 13, 708-712. [CrossRef]

34. Mao, C.X.; Zhou, Y.; Wu, Y.; Soewardiman, H.; Werner, D.H.; Jur, J.S. Low-Profile Strip-Loaded Textile Antenna with Enhanced Bandwidth and Isolation for Full-Duplex Wearable Applications. IEEE Trans. Antennas Propag. 2020, 68, 6527-6537. [CrossRef]

35. Chin, K.-S.; Wu, C.-S.; Shen, C.-L.; Tsai, K.-C. Designs of Textile Antenna Arrays for Smart Clothing Applications. Autex Res. J. 2018, 18, 295-307. [CrossRef] 